www.nature.com/pj

\title{
Specific gold ion scavenger by means of sol-gel transition of peptide copolymer
}

\author{
Satoshi Tanimoto, Tohru Okunishi, Hitoshi Yamaoka and Yoshitsugu Hirokawa
}

Novel procedure is proposed to recover noble metals by means of extraction of the metal ion from a dilute aqueous solution to chloroform solution containing polyleucine-block-polyethylene glycol-block-polyleucine followed by the separation of the chloroform gel phase induced by the thermo-sensitive sol-gel transition. A characteristic specificity of the peptide copolymer gel for $\mathrm{Au}^{3+}$ was found and number of capture-sites per one copolymer chain and adsorption equilibrium constants between the capture-site and one $\mathrm{Au}^{3+}$ ion were evaluated, and then the capturing mechanism was discussed. It was thus clarified that $\mathrm{Au}^{3+}$ ion was captured by the amino group of the chain end of the peptide copolymer and that the equilibrium constant of the binding was larger than that of $\mathrm{Pd}^{2+}$ and $\mathrm{Pt}^{4+}$ ions.

Polymer Journal (2011) 43, 313-316; doi:10.1038/pj.2010.138; published online 19 January 2011

Keywords: adsorption; block copolymer; gelation; peptides; selectivity

\section{INTRODUCTION}

Technological advances of recent years are supported by the various kinds of novel materials. Especially, noble metals are remarkably important in the information technology industries, which support today's society. In order to receive the full benefit of technological success, the depletion of resources is becoming more crucial problems, and we have to seriously intend to solve the sustainable use of resources. One of the resolutions of the issues is a cyclical use of noble metal resources. There have been many attempts of recovering noble metals in aqueous systems. ${ }^{1-4}$ A liquid-liquid extraction techniques of metal ions with organic solvents have been traditionally studied for many years. Parajuli et al. have energetically investigated lignophenol derivatives as an adsorbent for noble metal ions such as $\mathrm{Au}(\mathrm{III}), \mathrm{Pd}(\mathrm{II})$ and $\mathrm{Pt}(\mathrm{IV}) .^{5-7}$ Recently, there appeared some reports that the environment-conscious materials such as yeast funguses and chitosan from crab shell could be applied as a noble metal ion adsorbent. ${ }^{8-10}$ Most studies are carried out to develop a new functional adsorbent having a high selectivity or specificity for the noble metal ions. In order to achieve the high efficiency and the high selectivity, we have to use the materials having a characteristic interaction with the metal ions in water. As there have been many reports on various peptides interacting with metal ions, ${ }^{11-14}$ we focused on the peptides as the materials with characteristic interaction with metal ions. We have already reported the peptide copolymer gel method and the copolymer effectively served as a recovering adsorbent having the characteristic interaction with the organic compound such as an endocrine disruptor. ${ }^{15}$

In the present study, 'Peptide copolymer gel method', which is a extraction of metal ions from water layer into oil layer followed by the separation of oil layer by means of sol-gel transition, was applied to scavenge the noble metal ions, such as $\mathrm{Au}, \mathrm{Pt}$ and $\mathrm{Pd}$ ions, from the dilute aqueous solution.

\section{EXPERIMENTAL PROCEDURE}

Synthesis of peptide copolymer

The ABA type triblock copolymer consist of polyleucine as hydrophobic segments (A) and polyethylene glycol (PEG) as a hydrophilic center segment (B) was synthesized through a ring-opening polymerization of L-leucine $\mathrm{N}$-carboxyanhydride by a PEG macro-initiator having two amino-terminal groups. The details of the synthesis procedures were described in the previous paper. ${ }^{15}$ The amino-terminated PEG (molecular weight: 3400 ) was purchased from NOF Corporation (Tokyo, Japan). The ABA triblock copolymer was hereafter referred to as 'Peptide copolymer'. The characterization of the synthesized copolymers was investigated by nuclear magnetic resonance (Lambda400 of JEOL, Akishima, Japan) and gel permeation chromatography (10A series of Shimadzu, Kyoto, Japan with polystyrene columns purchased from Polymer Laboratory, Shropshire, UK; Scheme 1).

Metal ion capture (peptide copolymer sol-gel transition method) Figure 1 schematically shows the experimental procedure capturing the metal ion from an aqueous solution. At first, the commercially available metal ions standard solutions (1000 p.p.m., Wako Pure Chemical Industries, Ltd, Osaka, Japan) were diluted with $1 \mathrm{moll}^{-1}$ of hydrochloric acid to obtain a variety of concentrations of the solution. Then, $1 \mathrm{wt} \%$ chloroform solution $(1 \mathrm{ml})$ of peptide copolymer was added to the metal ion aqueous solution $(4 \mathrm{ml})$ at drop by drop. After vigorous stirring of the mixture for $1 \mathrm{~min}$, the suspended mixture was kept in a warm bath setting at $40^{\circ} \mathrm{C}$ until the boundary between water and chloroform layers became clear. Then, it was cooled down to $5^{\circ} \mathrm{C}$ to induce the gelation of the chloroform layer. After the completion of gelation of chloroform layer, the water layer was removed by decantation and the concentration change of the metal ion 
in the water phase was evaluated with inductively coupled plasma (ICP) spectroscopy (Ultima 2, HORIBA, Ltd, Kyoto, Japan).

The gelation of the chloroform solution of the peptide copolymer is caused by the aggregation of polyleucine blocks induced by the temperature change. The metal ions, which we are going to capture, exist in an aqueous phase. In order for the peptide block to interact with the metal ions in the aqueous phase, the peptide copolymer should have a hydrophilic segment such as PEG blocks. The introduction of the PEG block into the peptide block, therefore, is expected to increase the affinity to water.

\section{RESULTS AND DISCUSSION}

Polymer characterization

Nuclear magnetic resonance spectrum of the copolymer was shown in Figure 2. The polymerization degree of the peptide copolymer synthesized in this study was calculated by the ratio of peak areas due to the three resonances at 3.2 p.p.m. (terminal methylene protons of amino-PEG), 3.8 p.p.m. (methylene protons of amino-PEG main chain) and 0.9 p.p.m. (methyl protons of polyleucine side branch). The polymerization degree was found to be 25 for peptide block and 83 for PEG block.

Gel permeation chromatograph of the block copolymer was shown in Figure 3. The gel permeation chromatography shows a single peak, which may suggest no production of the peptide homopolymer as byproduct. The polydispersity index of the block copolymer characterized with gel permeation chromatography was 1.63 . The polymerization degree of the peptide segment was close to the value expected from the molar ratio of monomer and amino group of the macroinitiator, which also indicates the lack of polypeptide homopolymer.

The chloroform solution of the peptide copolymer showed a reversible thermo-sensitive sol-gel transition around room temperature. When the solution was cooled down to $15^{\circ} \mathrm{C}$, the solution became gel. On heating from $15^{\circ} \mathrm{C}$ to $40^{\circ} \mathrm{C}$, the gel changed to solution. Thus, this process was found to be a reversible one.<smiles>CC(C)CC(N)C(=O)O</smiles><smiles>CC(C)CC1NC(=O)OC1=O</smiles><smiles>CC(C)CCNC(CC(C)C)C(=O)NC(C)(C)NC(=O)C(CC(C)C)NC(C)(C)C</smiles>

Scheme 1 Schemes of peptide copolymer synthesis. DMF, dimethylformamide; PEG, polyethylene glycol; THF, tetrahydrofuran.
Concentration ( $1 \mathrm{wt} \%$ ) of the copolymer is high enough to undergo the sol-gel transition and form a rigid gel. The fact that the transition temperature between gel phase and sol phase became higher with increase of polyleucine segment length, which has already been reported in our previous paper. ${ }^{15}$ The longer polyleucine chain has a lower solubility in chloroform than the shorter one. The copolymer having a longer peptide segment, therefore, shows a higher sol-gel transition temperature. It was suggested that this network formation of the peptide copolymer gel was caused by the aggregation of peptide segment. And nuclear magnetic resonance signal of polyleucine segment of the peptide copolymer observed at the gel state was smaller than that observed at the sol state. This fact also suggests that the peptide chain has an important role in the sol-gel transition.

\section{Capture efficiency of metal ion species}

The peptide copolymer gel method was applied to evaluate the capture efficiency. The metal ions used were $\mathrm{Au}^{3+}, \mathrm{Cr}^{6+}, \mathrm{Pd}^{2+}, \mathrm{Pt}^{4+}, \mathrm{Fe}^{3+}, \mathrm{Co}^{2+}$ and $\mathrm{Ni}^{2+}$. The concentrations of metal ions in each solution before and after the process of the peptide copolymer gel method were
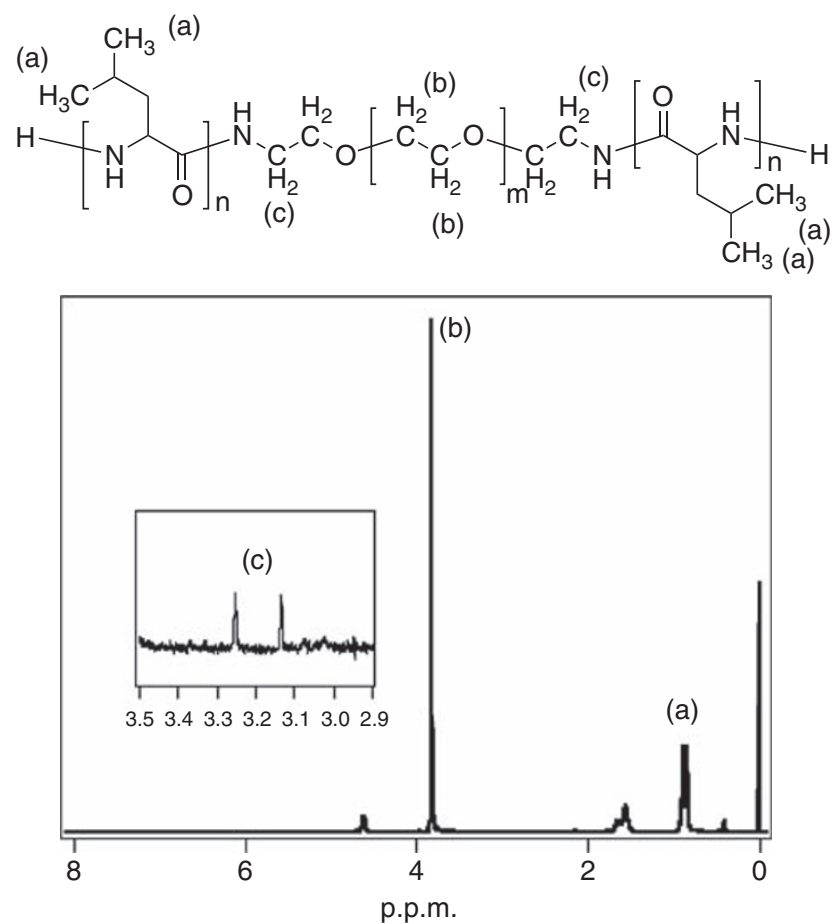

Figure $2{ }^{1} \mathrm{H}$ nuclear magnetic resonance (NMR) spectrum of the peptide copolymer used in this study. Solvent: trifluoroacetic acid-d. Temperature: $25^{\circ} \mathrm{C}$.
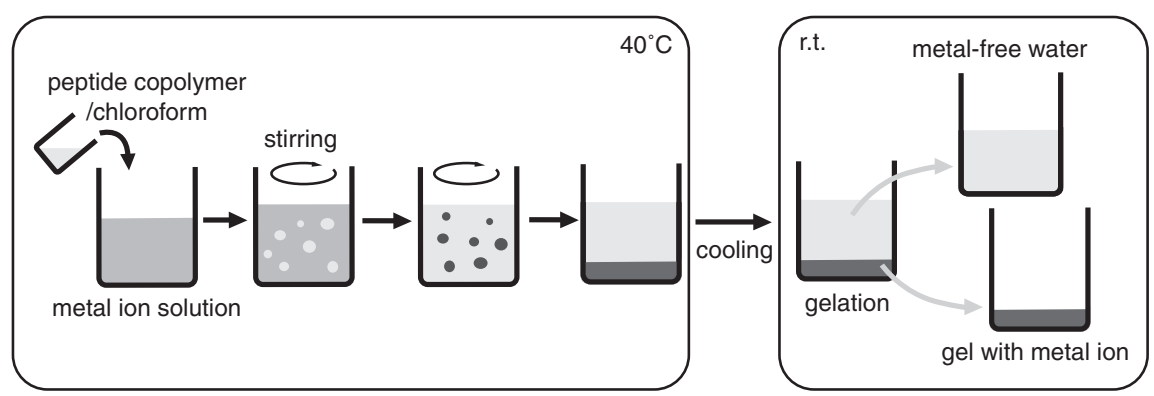

Figure 1 Schematic illustration of peptide copolymer gel method. 


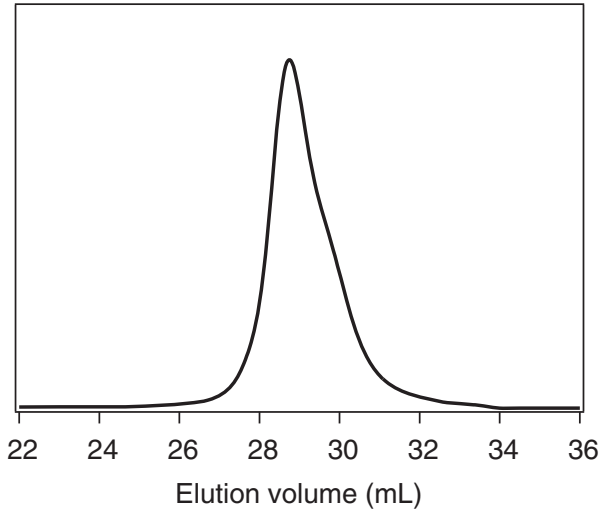

Figure $3 \mathrm{Gel}$ permeation chromatography profile of the peptide copolymer. Detected by refractive index. Eluent: chloroform.

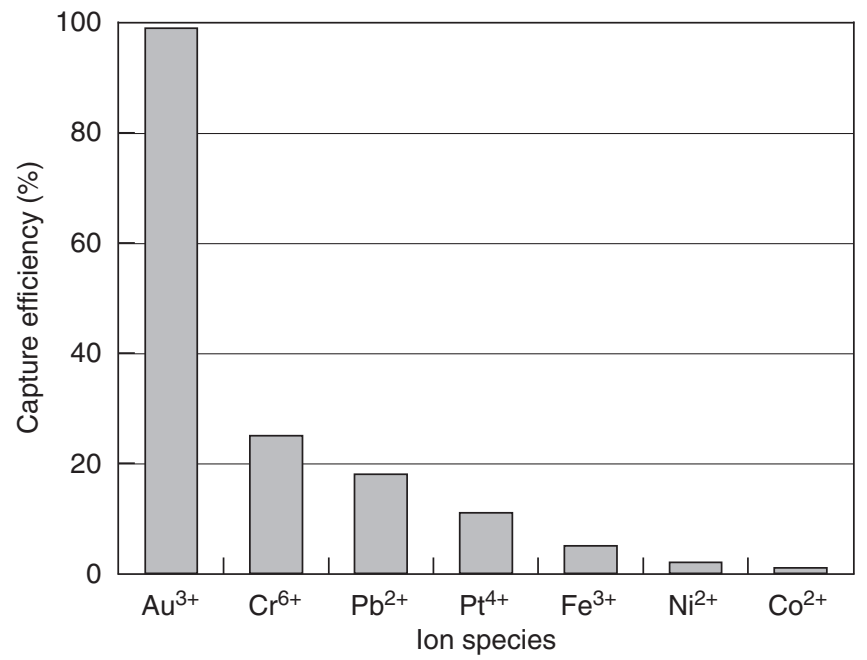

Figure 4 Capture efficiency of metal ion by the peptide copolymer gel method. The capture efficiency was calculated from the concentration difference between before and after capturing procedure obtained by ultraviolet spectroscopy.

measured by ICP. The capture efficiency for the 100 p.p.m. solution of each metal ion was summarized in Figure 4. Among the metal ions used, the capture efficiency for $\mathrm{Au}^{3+}$ ion was remarkably high and the value exceeded over $99 \%$. The result may indicate that there is a specific interaction between $\mathrm{Au}^{3+}$ and peptide copolymer. ${ }^{16,17}$

\section{Quantitative analysis of $\mathrm{Au}^{3+}$ ion capture}

The capture efficiency for $\mathrm{Au}^{3+}$ was especially high in comparison with other metal ions. We focused on the $\mathrm{Au}^{3+}$ ion capture by the peptide copolymer gel method and further quantitatively analyzed the capturing behavior in order to clarify the origin of the specificity.

\section{Estimation of capturing equilibrium constant}

At first, we assumed an adsorption equilibrium model that the metal ions equilibrated with binding sites on the peptide copolymer. The desorption equilibrium constant $(K)$, which is the reciprocal value of the adsorption equilibrium constant, is represented as follows:

$$
K=[\mathrm{M}][\mathrm{S}] /[\mathrm{MS}]
$$

where $[\mathrm{M}]$ is the concentration of metal ion, $[S]$ the concentration of unoccupied binding site on the copolymer and [MS] that of occupied
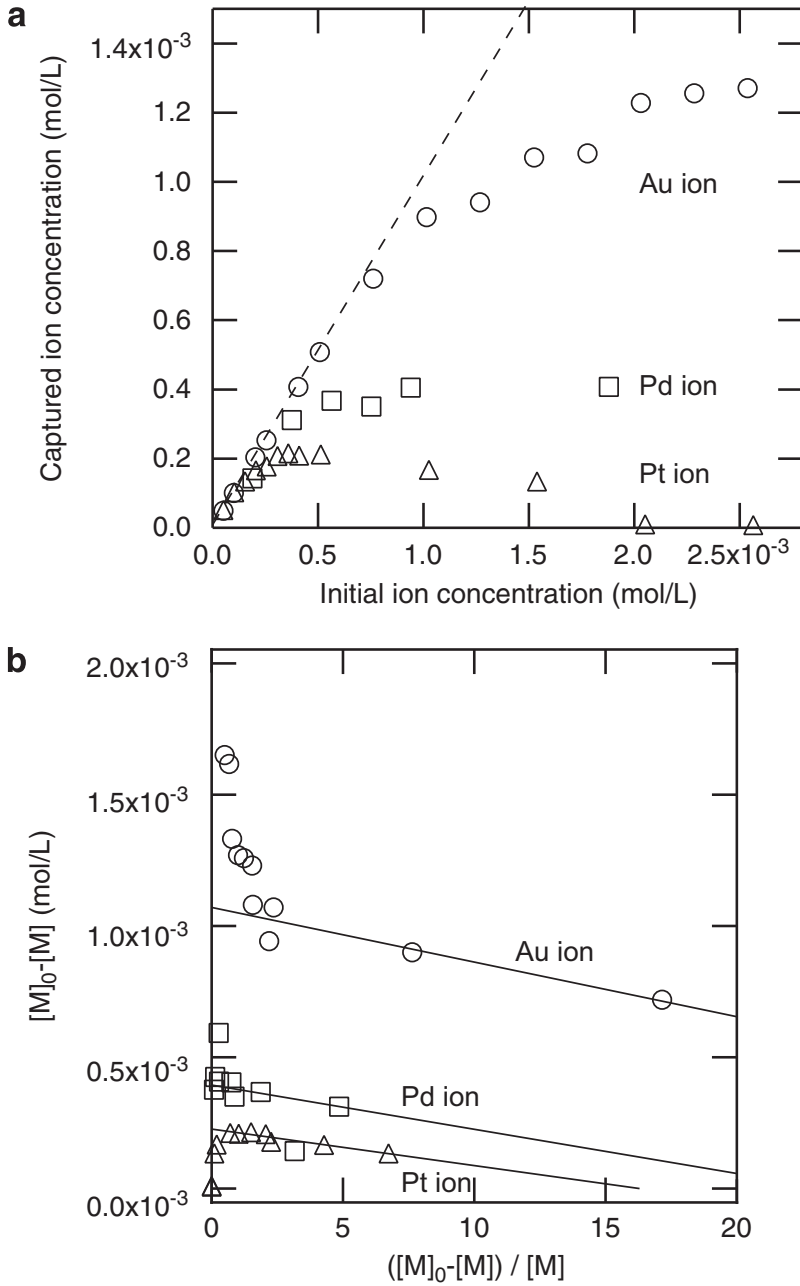

Figure 5 (a) Results of peptide copolymer gel method for noble metal ions, $\mathrm{Au}, \mathrm{Pd}$ and Pt. (b) Linear plots for Au, Pd and Pt ions based on Equation 3.

binding site. The relation among [MS], initial metal ion concentration $[\mathrm{M}]_{0}$ and initial binding site concentration $[\mathrm{S}]_{0}$ is shown in Equation 2.

$$
[\mathrm{MS}]=[\mathrm{M}]_{0}-[\mathrm{M}]=[\mathrm{S}]_{0}-[\mathrm{S}]
$$

Equation 3 can be obtained when Equation 2 is substituted for Equation 1.

$$
[\mathrm{M}]_{0}-[\mathrm{M}]=-K\left([\mathrm{M}]_{0}-[\mathrm{M}]\right) /[\mathrm{M}]+[\mathrm{S}]_{0}
$$

Therefore, the plot should hold linear relationship when the concentration change of the metal ion $\left([\mathrm{M}]_{0}-[\mathrm{M}]\right)$ is plotted as a function of $\left([\mathrm{M}]_{0}-[\mathrm{M}]\right) /[\mathrm{M}]$. Consequently, the desorption equilibrium constant, $K$, and the initial binding site concentration, $[\mathrm{S}]_{0}$, can be obtained from the slope of the plot and the intercept on the vertical axis, respectively.

\section{Number of $\mathrm{Au}^{3+}$ binding sites on the peptide copolymer}

In order to discuss the Au capturing mechanism, we estimated the number of binding site per one copolymer and analyzed the location of the Au capture site in the copolymer. The capture experiments were done with Au aqueous solutions of which concentrations were ranging from 10 to 500 p.p.m. (from $5.08 \times 10^{-5}$ to $2.54 \times 10^{-3} \mathrm{moll}^{-1}$ ). Same experiments were carried out for other metal ions such as $\mathrm{Pd}^{2+}$ and $\mathrm{Pt}^{4+}$ in order to compare the specificity with $\mathrm{Au}^{3+}$ ion. The results were plotted in Figure 5 for $\mathrm{Au}, \mathrm{Pd}$ and Pt ions. In Figure 5a, the concentrations of the captured metal ion were plotted as a function of 
Table 1 Parameters, $K,[S]_{0}$ and number of binding site per one copolymer for $\mathrm{Au}, \mathrm{Pd}$ and $\mathrm{Pt}$ ions

\begin{tabular}{lccc}
\hline Metal ion & $\mathrm{K}$ & {$[\mathrm{S}]_{0}\left(\mathrm{~mol} \mathrm{I}^{-1}\right)$} & $\begin{array}{c}\text { Number of binding } \\
\text { site per one copolymer }\end{array}$ \\
\hline $\mathrm{Au}^{3+}$ & $1.9 \times 10^{-5}$ & 0.0010 & 2.2 \\
$\mathrm{Pd}^{2+}$ & $1.7 \times 10^{-5}$ & 0.00040 & 0.89 \\
$\mathrm{Pt}^{4+}$ & $1.4 \times 10^{-5}$ & 0.00022 & 0.49 \\
\hline
\end{tabular}

the initial concentration of each metal ion species. When the initial concentration of $\mathrm{Au}^{3+}$ is lower than 200 p.p.m. $\left(1.02 \times 10^{-3} \mathrm{moll}^{-1}\right)$, over the $90 \%$ of $\mathrm{Au}^{3+}$ was adsorbed. On the other hand, in the region beyond 200 p.p.m., the capture efficiency decreased. That is, there is a kink in the quantity that the peptide copolymer gel could capture the metal ion, which might indicate that a number of specific functional group or a specific molecular structure was related to capture $\mathrm{Au}^{3+}$ ions.

Figure $5 \mathrm{~b}$ showed the plots based on Equation 3. The slope and the intercept were obtained from a linear fitting in the appropriate range of the plots. The obtained slope showed a desorption equilibrium constant, and the intercept showed an initial binding site concentration $[S]_{0}$ in the system. The number of the binding site per one copolymer was evaluated as 2.2 from a ratio of the copolymer concentration (that is, $0.00045 \mathrm{moll}^{-1}$ ) and $[S]_{0}$. When the number of the binding sites per one copolymer and its molecular structure are taken into account, it is reasonably acceptable that the amino groups at the both terminal end of the peptide copolymer interacted with two $\mathrm{Au}^{3+}$ ions. This speculation was supported by the fact that the number of the binding site per one copolymer was almost two irrespective of the peptide segment length.

\section{Comparison of $\mathrm{Au}^{3+}$ ion with $\mathrm{Pt}$ and $\mathrm{Pd}$ ions}

The adsorption behavior of $\mathrm{Au}^{3+}$ was obviously different from those of $\mathrm{Pt}$ and Pd ions. The linear plots for Pd and Pt ions were also shown in Figure 5b. From the Figure 5b, the desorption equilibrium constant, the initial binding site concentration and the number of the binding sites per one copolymer were obtained and summarized in Table 1 . Judging from the desorption equilibrium constant value, each value is rather close to one after another. On the other hand, the number of binding site per one copolymer is quite different, which suggests that the binding mechanism of $\mathrm{Au}^{3+}$ is different from that of $\mathrm{Pd}$ and $\mathrm{Pt}$ ions. The difference in the coordination structure depending on the variation of ion species is plausible as a reason. Further study is necessary to understand the detail mechanism.

\section{CONCLUSION}

ABA-type peptide copolymers containing PEG and poly(L-leucine) chains were synthesized by a ring-opening polymerization of $\alpha$-amino acid $N$-carboxyanhydride with PEG macro-initiator having two amino-terminal groups. The chloroform solution of the peptide copolymer showed a thermo-sensitive sol-gel transition. And it became clear that the peptide copolymer gel can be used as an effective $\mathrm{Au}^{3+}$ scavenger from its dilute aqueous solution with simple three steps (stirring, cooling and decantation). This process proposed in this study will be applied to the environmentally harmonized water treatment in the near future.

\section{ACKNOWLEDGEMENTS}

This study was supported, in part, by a grant for 'The Development of Base Technology for the Construction of Environmentally Harmonious Industrial Systems' promoted by Shiga Prefecture under the program of Collaboration of Regional Entities for the Advancement of Technological Excellence by Japan Science and Technology Agency. We acknowledge Dr Kimio Sumaru of National Institute of Advanced Industrial Science and Technology, Japan for his valuable suggestion on the data processing procedure.

1 Das, A., Vidyadhar, A. \& Mehrotra, S. P. A novel flowsheet for the recovery of metal values from waste printed circuit boards. Resour., Conserv. Recycling 53, 464-469 (2009).

2 Das, N. Recovery of precious metals through biosorption - A review. Hydrometallurgy 103, 180-189 (2010).

3 Huang, K., Guo, J. \& Xu, Z. Recycling of waste printed circuit boards: a review of current technologies and treatment status in China. J. Hazard. Mate. 164, 399-408 (2009).

4 Park, Y. J. \& Fray, D. J. Recovery of high purity precious metals from printed circuit boards. J. Hazard. Mater. 164, 1152-1158 (2009).

5 Parajuli, D., Hirota, K. \& Inoue, K. Trimethylamine modified lignophenol for the recovery of precious metals. Ind. Eng. Chem. Res. 48, 10163-10168 (2009).

6 Parajuli, D., Inoue, K., Kawakita, H., Ohto, K., Harada, H. \& Funaoka, M. Recovery of precious metals using lignophenol compounds. Miner. Eng. 21, 61-64 (2008).

7 Kawakita, H., Yamauchi, R., Parajuli, D., Ohto, K., Harada, H. \& Inoue, K. Recovery of gold from hydrochloric acid by means of selective coagulation with persimmon extract. Sep. Sci. Technol. 43, 2375-2385 (2008).

8 Mack, C. L., Wilhelmi, B., Duncan, J. R. \& Burgess, J. E. Recovery of platinum ions from aqueous solution by immobilized Saccharomyces cerevisiae biomass: a kinetic analysis. Miner. Eng. 21, 31-37 (2008).

9 Mack, C., Wilhelmi, B., Duncan, J. R. \& Burgess, J. E. Biosorption of precious metals. Biotechnol. Adv. 25, 264-271 (2007).

10 Fujiwara, K., Ramesh, A., Maki, T., Hasegawa, H. \& Ueda, K. Adsorption of platinu$m(I V)$, palladium(II) and gold(III) from aqueous solutions onto L-lysine modified crosslinked chitosan. J. Hazard. Mater. 146, 39-50 (2007).

11 Smith, M. C., Furman, T. C., Ingolia, T. D. \& Pidgeon, C. Chelating peptide-immobilized metal ion affinity chromatography. A new concept in affinity chromatography for recombinant proteins. J. Biol. Chem. 263, 7211-7215 (1988).

12 Hutchens, T. W., Nelson, R. W., Allen, M. H., Li, C. M. \& Yip, T. Peptide-metal ion interactions in solution: detection by laser desorption time-of-flight mass spectrometry and electrospray ionization mass spectrometry. Biol. Mass Spectrom. 21, 151-159 (1992).

13 Arnold, F. H. Metal-affinity separations: a new dimension in protein processing. Biotechnology 9, 151-156 (1991).

14 Green, L. M. \& Berg, J. M. A retroviral Cys-Xaa2-Cys-Xaa4-His-Xaa4-Cys peptide binds metal ions: spectroscopic studies and a proposed three-dimensional structure. Proc. Natl Acad. Sci. USA 86, 4047-4051 (1989).

15 Tanimoto, S., Yagi, N. \& Yamaoka, H. Application of thermosensitive peptide copolymer gels to removal of endocrine disruptor. Res. Lett. Mater. Sci. 2009, 1-4 (2009).

16 Sheardown, H., Cornelius, R. M. \& Brash, J. L. Measurement of protein adsorption to metals using radioiodination methods: a caveat. Colloids Surf B Biointerfaces 10, 29-33 (1997).

17 Davis, J. J., Halliwell, C. M., Hill, H. A. O., Canters, G. W., van Amsterdam, M. C. \& Verbeet, M. P. Protein adsorption at a gold electrode studied by in situ scanning tunnelling microscopy. New J. Chem. 22, 1119-1123 (1998). 